\title{
Coordinating a Collegiate Service-Learning Mentoring Program ${ }^{1}$
}

\author{
Emily Rickerson, Matthew Ohlson, Kate Fogarty, Muthusami Kumaran, and Dale Pracht ${ }^{2}$
}

Mentoring has been shown to provide a mutually beneficial relationship to those involved. Both mentors and mentees have seen improvement in areas such as leadership skill development, increases in academic achievement, attendance in school, and lower instances of substance abuse (Ohlson, 2009; Grossman \& Tierney, 1998). University of Florida is host to a model for mentoring programs-known as C.A.M.P. (Collegiate Achievement Mentoring Program) Gator, the program involves a service-learning course where college students serve as mentors to at-risk elementary and middle school students. Service-learning involves reflection as well as action and combines community work with classroom instruction and course requirements (Schutz \& Gere, 1998). Service-learning programs such as C.A.M.P. Gator have been shown to foster self-efficacy, leadership skills, and a sense of civic responsibility and community participation in college students (Vogelgesang \& Astin, 2000).

Developing a mentoring program at a collegiate-level institution involves a mutually beneficial relationship between college students, who grow in community involvement and understanding, and local elementary and middle school students, who receive academic support. This partnership utilizes the resources of a large academic institution to positively impact the surrounding community. Building a program like C.A.M.P. Gator for an institute of higher learning takes a great deal of planning, communication, and leadership. This article will discuss the steps required to coordinate such a program.

First, the structure of the mentoring course should include a team of individuals who are committed to making the program a success. A program structure should include the following roles (note that this structure can be adapted to meet the needs of a specific program and may include several persons in any given role):

- Director-in charge of the overall operation of the program, this team member develops and implements the course assignments, leads classes, leads discussions, arranges the mentor and mentee meetings, communicates with the school administrators, presents program findings to district, university, state, and national stakeholders.

- Program Coordinator-helps the Director with assigned tasks, develops activities for mentors and mentees to participate in together, supervises mentoring sessions, evaluates sessions, and program success

- Lead Mentor-someone who has previously participated in the course or has a background in mentoring that supports and guides the first time mentors, completes assigned tasks from the Director and Program Coordinator

1. This document is FCS9269, one in a series of the Department of Family, Youth and Community Sciences, Florida Cooperative Extension Service, Institute of Food and Agricultural Sciences, University of Florida. Published August 2011. Visit the EDIS website at http://edis.ifas.ufl.edu.

2. Emily Rickerson, graduate assistant, Department of Family, Youth and Community Sciences, University of Florida; Matthew Ohlson, executive director, Leadership Academy, NC State, and director, CAMP Gator, University of Florida; Kate Fogarty, assistant professor, Muthusami Kumaran, assistant professor, and Dale Pracht, assistant professor, Department of Family, Youth and Community Sciences, University of Florida. Contact author is Kate Fogarty, University of Florida, Gainesville, FL 32611. 
The second step will be communication with the school administrators at the college, specifically the department in which the course will take place. Every program will be unique in how it is structured and where it best fits with the current curriculum. Some examples of departments or colleges where it might fit include a Department / School / College of: Education, Human Development and Family Studies, Family and Consumer Sciences, Human Sciences, Public Health / Health Promotion, Public Service, or Social Work. Communication with university or college administrators is essential to assess their needs as well as to adapt the program's components to fit both program and school requirements.

The third step is to identify those local elementary/middle schools, afterschool programs for youth, or nonprofit organizations considered a good fit for the implementation of the mentoring program (schools or nonprofits that are located close to the college, those institutions serving a high percentage of at-risk students, etc.). Once the possible sites are located, meet with the school administrators and/or nonprofit organization leaders to discuss the program's components and the benefits for their students or participants. It is important to be specific as you emphasize the benefits that the schools/agencies will receive from the program; include factual details such as children who have participated in similar programs have experienced increased GPA's, decreased school suspensions, increased confidence, and enhanced public speaking ability (Ohlson, 2009). Preparation, therefore, is of great importance before walking into a meeting with school or agency staff. Preparing a brochure or handout that can be left with the school/ organization with an overview of the program, as well as contact information listed (e.g., e-mail, website), leaves a positive impression and can be used by the institution to send out to interested parties and answer any lingering questions they may have.

Finally, after the course is approved with the college or university and mentoring sites are established, the director and coordinator should incorporate the following steps into developing the program:

- Develop an outline for the course (course syllabus) including: course description, requirements, expectations, text and other resources used, assignments, learning objectives, timeline, and activities.

- Selection of mentors (students in the course)—college advisors will choose the students they believe would benefit most from the program; the college students are best selected by advisors and/or administrators from the department in which the program will be located based upon their academic and leadership success as well as interest in the program.

- Selection of mentees-the classroom teachers and the school administration should select students whom they feel could benefit the most from the mentoring process. At-risk students, such as those who struggle with negative academic and social/behavioral issues, are targeted for participation.

- Background verification on mentors-the selected college student mentors' background information profiles are to be given to schools and youth-serving institutions for background verification. Depending on the mentoring site, the college students may need to fill out forms asking for personal information such as criminal history, traffic violations, work history, etc.; driver's licenses may need to be scanned and personal references may need to be checked in order for a mentor to be able to work with youth. You will need to check with and work with the sponsoring elementary school to see what is required.

- Letters are to be sent home to parents or guardians for the "okay" on having their child participate as a mentee in the program. Inform parents about the screening process for mentors, the program evaluation process, and mentees' participation requirements. This is important for risk management and liability reasons.

- Schedule times and locations for mentoring sessionseach student will need to be provided with set days and times for their mentoring sessions to take place. Providing needed structure and routing will benefit mentors as well as mentees and will serve as a guidepost for accountability. Develop a schedule of times and days that will work for the schools/nonprofits to have the mentors come in (usually lunch time or after school works best for the mentees), then have the mentors choose which dates will work for them. Make sure the director, program coordinator, or a lead mentor is available to supervise each session.

- Utilize curriculum-based mentoring sessions-each mentoring session should incorporate a planned activity (e.g., a game, life-skill lesson, or homework help) or topic of conversation developed through research-based methodology. For example, C.A.M.P. Gator uses "The 7 Habits of Highly Effective Teens" by Sean Covey to develop activities and topics of conversation that work to improve participants' lifestyle choices and character. Incorporate proper opportunities for reflection such as 
reflective journaling, on-line discussions, or blog writing to connect the experience with the curriculum.

As mentioned, it's crucial that the director, program coordinator, or lead mentor be in attendance during mentoring sessions. This will give first-time mentors the support they need should any problems or questions arise that require immediate attention. In addition to reflection opportunities connected to curriculum, there should also be time for reflection at the end of the sessions for the mentors to share their questions, concerns, and overall experiences with program personnel. Reflection is a crucial part of the service-learning experience (Bringle \& Hatcher, 1996). This reflection can be done as a group or through journaling, but it is important that the youth have an opportunity to verbalize and process their experience with the mentor.

Besides the basic coursework, mentors can and should be urged to participate in other culminating projects. Opportunities here are abundant:

- grant writing (to raise money for local nonprofits in which their mentees attend or are served)

- virtual mentoring (mentoring via computer or other form of technology where mentors and mentees can communicate without physically being in the same location)

- conducting presentations of what they have learned and how others can make a difference to schools

- making videos to display the impact of the program

These types of projects—and much more-can be offered or suggested to the mentors to further their development.

\section{References}

Bringle, R.G. \& Hatcher, J.A. (1996). Implementing service learning in higher education. Journal of Higher Education 67(2): 221-239.

Grossman, J. B., \& Tierney, J. P. (1998). Does mentoring work? An impact study of the Big Brothers, Big Sisters program. Evaluation Review 22(3): 403-426.

Ohlson, M. (2009). C.A.M.P. Gator: Collegiate Achievement Mentoring Program. Journal for Civic Commitment 13(1).

Schutz, A. \& Gere, A. (1998). Service-learning and English Studies: Rethinking "Public" Service. College English 60(2): 129-149.
Vogelgesang, L. \& Astin, A. (2000). Comparing the effects of community service and service learning. Michigan Journal of Community Service-Learning 7(1): 25-34. 